\title{
Magnetoconvection in a Bidispersive Porous Media
}

\section{GUNDLAPALLY SHIVA REDDY ${ }^{1}$ and Ragoju Ravi ${ }^{1}$}

${ }^{1}$ National Institute of Technology Goa

December 27, 2020

\begin{abstract}
Thermal instability of magnetoconvection in a horizontal bidispersive porous layer, uniformly heated from below, is analyzed. To study the linear stability theory, we perturbed the basic state with small-amplitude disturbances. Then, the governing dimensionless equations are solved using the normal modes. By employing the one-term Galerkin weighted residuals method, the critical values of Rayleigh numbers for the onset of stationary and oscillatory instability, have been determined. The effect of Chandrasekhar number on the system was analyzed.
\end{abstract}

\section{Hosted file}

bidimagnetic.pdf available at https://authorea.com/users/385412/articles/500832magnetoconvection-in-a-bidispersive-porous-media 